\title{
Test Study on Strength and Permeability Properties of Lime-Fly Ash Loess under Freeze-Thaw Cycles
}

\author{
Zhiquan Zhang ${ }^{1}$ and Yufen Zhang ${ }^{2, *}$ \\ ${ }^{1}$ School of Civil Engineering, Chang'an University, Xi'an, P.R. China 710061 \\ ${ }^{2}$ College of Architecture and Civil Engineering, North China University of Technology, Beijing, P.R. China, 100144
}

\begin{abstract}
In order to study the application of lime-fly ash loess in permafrost subgrade engineering, uniaxial compressive test, fast direct shearing test and permeability tests were carried out on lime-fly ash loess under different curing ages and freeze-thaw cycles. Uniaxial compressive strength of lime-fly ash loess increases slowly with the curing ages, and can reach 3.5 Mpa after the curing ages of 90 days (This strength is called 90d strength). 14d strength of lime-fly ash loess has already reached $50 \%$ of $90 \mathrm{~d}$ strength; later strength including $28 \mathrm{~d}$ strength and $90 \mathrm{~d}$ strength is basically stable under different freeze-thaw cycles, so lime-fly ash loess has good water stability and freeze-thaw stability. Fast direct shear strength decreases with the number of freeze-thaw cycles without consideration of moisture content; the coefficient of permeability increases with the number of freeze-thaw cycles. All test data show that lime-fly ash loess with good behaviors can be applied in permafrost subgrade engineering.
\end{abstract}

Keywords: 90d strength, freeze-thaw cycles, lime-fly ash loess, subgrade engineering, water-saturated.

\section{INTRODUCTION}

Loess with special mechanical property, is widely distributed in China. Especially in highway construction of West China, it is inevitable to encounter the problem of loess soil. Lime is a very cheap material and widely used to stabilize the loess, and this method has been used for more than thousand years. Recently, many scholars have studied the mechanism of stabilizing soil and the micro-reaction mechanism between lime and soil [1,2], and some important achievements have been obtained. Some works were also done with the strength increasing process and discipline of loess or clay [3-5]. Feng (2008) has carried out shearing test to study the strength characteristics of fine particle soils under the effect of freeze-thaw cycles [6], and found that the strength of lime soil decreased obviously under freeze-thaw cycles. However, there are few studies on lime-fly ash loess about water stability, freeze-thaw stability and permeability. Lime-fly ash loess can be used in road engineering in permafrost regions and seasonal permafrost zone, so the strength and deformation properties of lime-fly ash loess due to repeated freezing and melting can influence the life of the project under freeze-thaw cycles. In this paper, uniaxial compressive test, fast direct shearing test and permeability test were carried out on lime-fly ash loess under different curing ages and freeze-thaw cycles; the analysis focused on the strength characteristics and permeability of lime-fly ash loess.

*Address correspondence to this author at the College of Architecture and Civil Engineering, North China University of Technology, Beijing, P.R. China, 100144; Tel: 86-13522998929; Fax: 86-010-88803940;

E-mails: zzqca@163.com and yufenzh@gmail.com

\section{TEST MATERIALS AND TEST METHODS}

\subsection{Test Materials}

Test soil was taken from Highway Liu Zhong in China. Its main physical properties index is: soil proportion 2.713 , plasticity index 11.2 , liquid limit $29.2 \%$, and plastic limit $18 \%$; particles larger than $0.05 \mathrm{~mm}$ account for $15 \%$, particles between $0.005 \mathrm{~mm}$ to $0.05 \mathrm{~mm}$ account for $66 \%$, and particles smaller than $0.005 \mathrm{~mm}$ account for $19 \%$. The physical properties of fly ash are as follows: apparent density $2.17 \mathrm{~g} / \mathrm{cm}^{3}$, maximum dry density $1.15 \mathrm{~g} / \mathrm{cm}^{3}$, optimum moisture content $34.5 \%$. Main chemical composition is: $\mathrm{SiO}_{2}$ $61.2 \%, \mathrm{Al}_{2} \mathrm{O}_{3} 22.5 \%, \mathrm{Fe}_{2} \mathrm{O} 35 \%, \mathrm{CaO} 0.7 \%$. The lime in the tests was digestion lime with strong dry activity.

\subsection{Test Methods}

Ratio and dry density, moisture content and other parameters were referenced from the foregoing test results about strength characteristics of lime-fly ash loess [7], the volume ratio of lime, fly ash and loess is 1:2:7. The specimens were made with maximum dry density 1.57 $\mathrm{g} / \mathrm{cm}^{3}$, optimum water content $23.5 \%$, and compaction degree $97 \%$. Specimens were made into cylinder with the size of $\Phi 40 \mathrm{~mm} \times 100 \mathrm{~mm}$. There were three specimens in each group, and averaged result was taken. All the tests were performed according to the experiment specification of highway soil (JTG E40-2007) [8].

Uniaxial compressive strength tests adopted watersaturated lime-fly ash loess to simulate the road sub-base. The lime-fly ash loess can suck groundwater due to the negative pore water pressure, and water content will decrease through transpiration and evaporation, so moisture ratio 
continuously changes. In order to simulate this process, permeable rocks were placed at both ends of the specimen, and the specimen wrapped with rubber membrane was put in a laboratory sink. Water level was $5 \mathrm{~cm}$ above the top surface of the permeable rock. Then the specimen can suck water through the permeable rock because of the negative pore water pressure. This water-saturated process lasted for 48 hours.

According to the achievement of Viklander [9], soil's strength was going to be stable after $3 \sim 5$ freeze-thaw cycles. So the test adopted six freeze-thaw cycles maximum. Freeze-thaw cycles can simulate the natural temperature decrease from autumn to winter gradually, and the soil temperature was also gradually decreased from the upper portion to the bottom. Therefore, temperature fields were added at the top surface and the bottom surface of the specimen to decline the temperature. There was temperature difference $5^{\circ} \mathrm{C}$ between the top and the bottom. Temperature change rate was set to $4^{\circ} \mathrm{C} / \mathrm{h}$, from $+15^{\circ} \mathrm{C}$ to $-5^{\circ} \mathrm{C}$, then back to $+15^{\circ} \mathrm{C}$, one cycle lasted 10 hours.

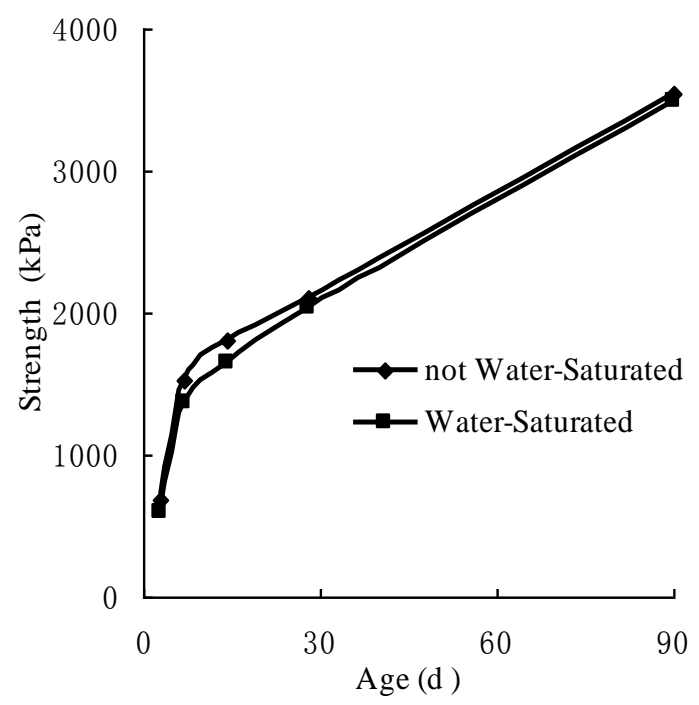

Fig. (1). Uniaxial compressive strength trend lines.

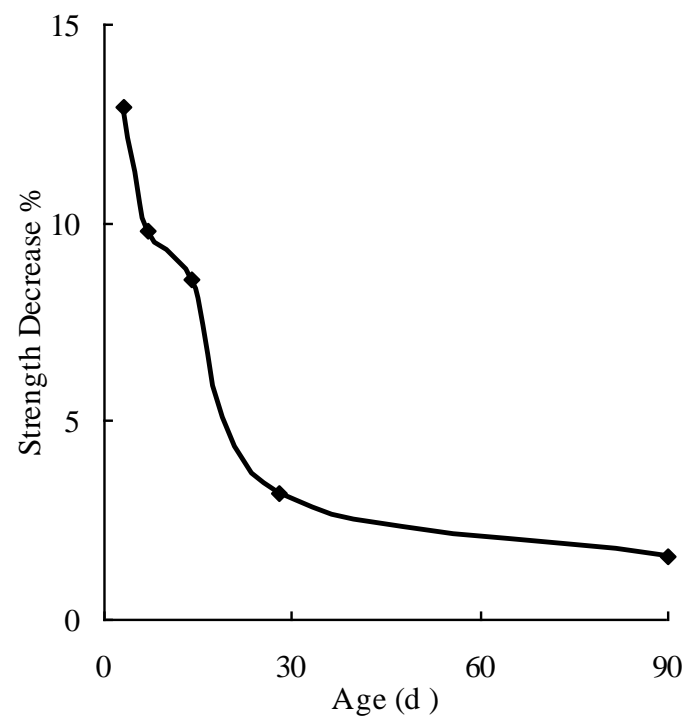

Fig. (2). Strength decrease after water-saturated.

\section{TEST RESULTS}

\subsection{Uniaxial Compressive Strength Test}

The results of uniaxial compressive strength tests of water-saturated lime-fly ash loess are shown in Figs. ( $\mathbf{1}$ and 2). As can be seen from Fig. (1), uniaxial compressive strength of lime-fly ash loess increases with the curing ages, especially before 14 days. 14d strength increases quickly and can reach nearly $50 \%$ of the $90 \mathrm{~d}$ strength. Fig. (2) shows the strength decrease of non-water-saturated lime-fly ash loess compared to not water-saturated specimens. Saturated water will reduce the uniaxial compressive strength of lime-fly ash loess especially for the earlier strength, such as $13 \%$ decreased for $7 \mathrm{~d}$ strength and $8.6 \%$ decreased for $14 \mathrm{~d}$ strength. However, there are no evident strength decrease for later strength including $28 \mathrm{~d}$ strength and $90 \mathrm{~d}$ strength, such as $3.2 \%$ decreased for $28 \mathrm{~d}$ strength and only $1.6 \%$ decreased for $90 \mathrm{~d}$ strength. Strength was decreased by $2.4 \%$ on average for the later strength. The phenomena are due to ion exchange, hydration and carbonation effect among fly ash, lime and soil. During the process of saturated water, these three reactions are weakened, making a long strength formation process, so there is certain water-hardening characteristic in lime-fly ash loess. Over the curing time, the cementation reaction lime-fly ash loess becomes more fully, then water, ions, and air cannot enter into the dense soil particles, so the strength decrease starts to be smaller and smaller. The average value of $7 \mathrm{~d}$ strength, $14 \mathrm{~d}$ strength and $28 \mathrm{~d}$ strength of water-saturated lime-fly ash loess was only reduced by $7.3 \%$, while $25 \%$ reduced for water-saturated cement-lime soil according to the research on the stability of cement-lime soil [10]. Therefore, lime-fly ash has better water stability under normal curing condition.

The uniaxial compressive tests were conducted on limefly ash loess under different freeze-thaw cycles. All the test data were compared to the specimens under normal condition without freeze-thaw condition. Strength decrease of lime-fly ash loess after different freeze-thaw cycles is shown in Fig. (3). Strength decrease of water-saturated limefly ash loess after different freeze-thaw cycles is shown in Fig. (4).

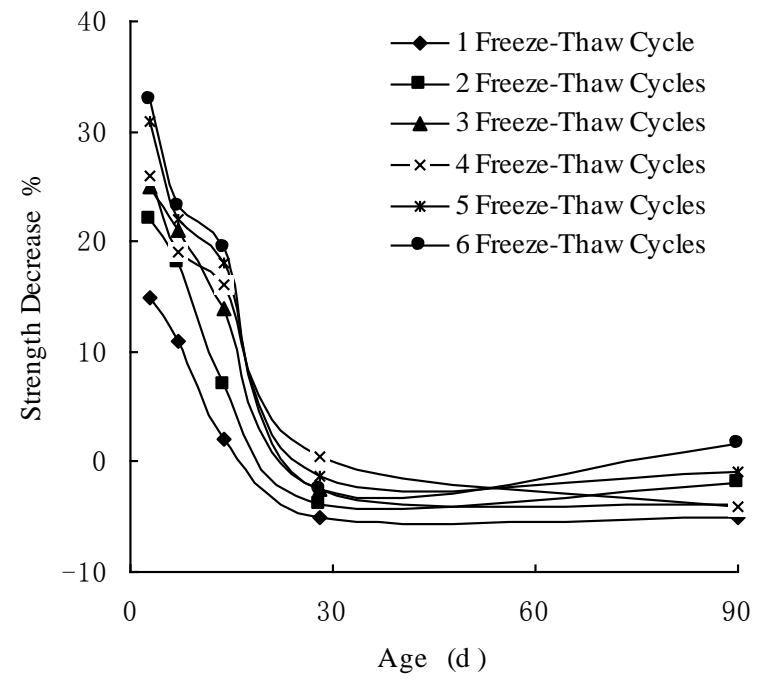

Fig. (3). Strength decrease of lime-fly ash loess. 
It can be seen from Fig. (3) that freeze-thaw cycles have great impact on earlier uniaxial compressive strength including $7 \mathrm{~d}$ strength and $14 \mathrm{~d}$ strength. Average strength has been reduced by $19 \%$. However, there are basically no effects on the later strength including $28 \mathrm{~d}$ strength and $90 \mathrm{~d}$ strength with only $2 \%$ reduction on average. It can be seen from Fig. (4) that freeze-thaw cycles have greater impact on uniaxial compressive strength of water-saturated lime-fly ash loess. Average earlier strength has already reduced by $47.9 \%$, and the later strength still reduced by $14.6 \%$. Especially after 5 and 6 freeze-thaw cycles, strength decrease becomes larger and larger for water-saturated lime-fly ash loess. The reason is that strength of lime-fly ash loess is formed by a long-term reaction process. Cold-contraction produced by temperature decreases results in the initial gel in tension, then many tiny cracks can greatly reduce the tensile strength of lime-fly ash loess before 28 days because there is a strength weakened zone; while less cracks occur when lime-fly ash loess after 28 days endure several freeze-thaw cycles. In case of watersaturated lime-fly ash loess, volume expansion by frozen water results in the improved permeability of the specimen, especially for lime-fly ash loess before 28 days. More test data about strength decrease within 4 freeze-thaw cycles are shown in Fig. (5). The average decrease has reached by $41.9 \%$ for earlier strength and $7.5 \%$ for later strength. All these analyses show that lime-fly ash loess compared to the other cement-lime soil or clays, has better freeze-thaw stability.

\subsection{Direct Shear Test}

Fast direct shear tests were conducted on lime-fly ash loess with the optimum water content less than 90 days' curing, ignoring the differences among moistures. The specimens experienced 0-6 freeze-thaw cycles, and the corresponding normal stress is $400 \mathrm{kPa}$. The shear stress, cohesion, and internal friction angle are shown in Figs. (6-8) respectively.

As can be seen from Fig. (6), 90d shear strength decreases continuously with freeze-thaw cycles. Shear stress

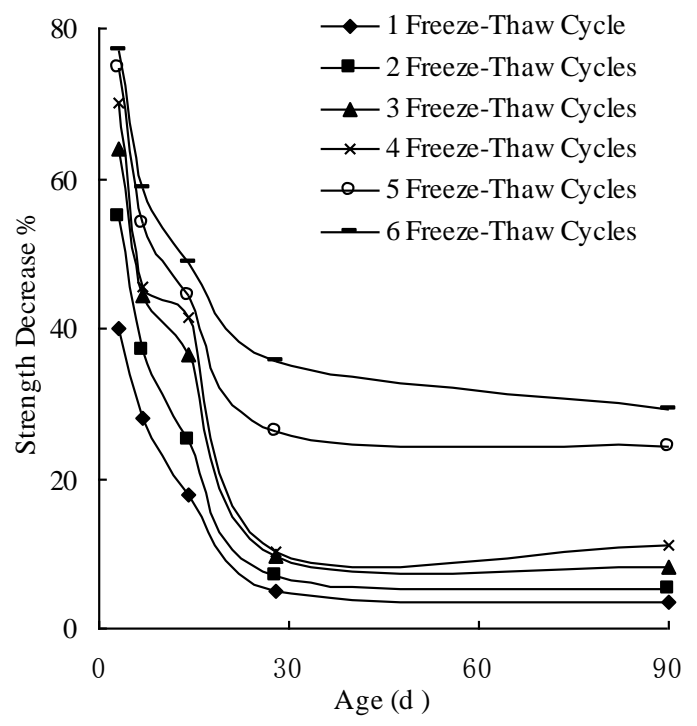

Fig. (4). Strength decrease of water-saturated lime-fly ash loess. after 6 freeze-thaw cycles is reduced by $21 \%$. However, the cohesion was changed with the freeze-thaw cycles irregularly shown in Fig. (7). Because the cohesion is the linear fit to empirical value according to three different

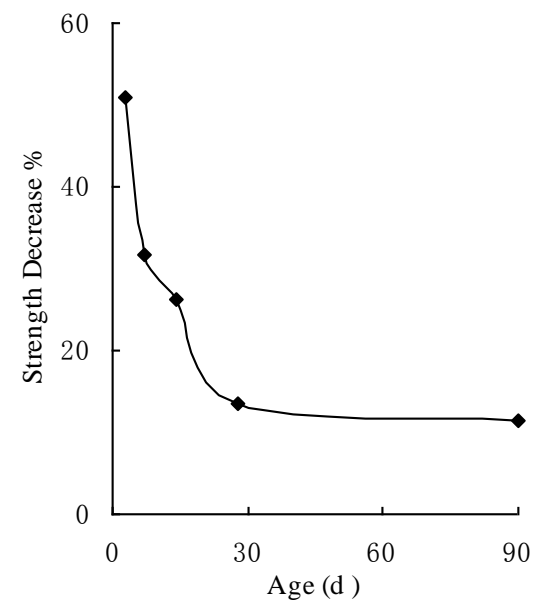

Fig. (5). Strength decrease of water-saturated lime-fly ash loess within 4 freeze-thaw cycles.

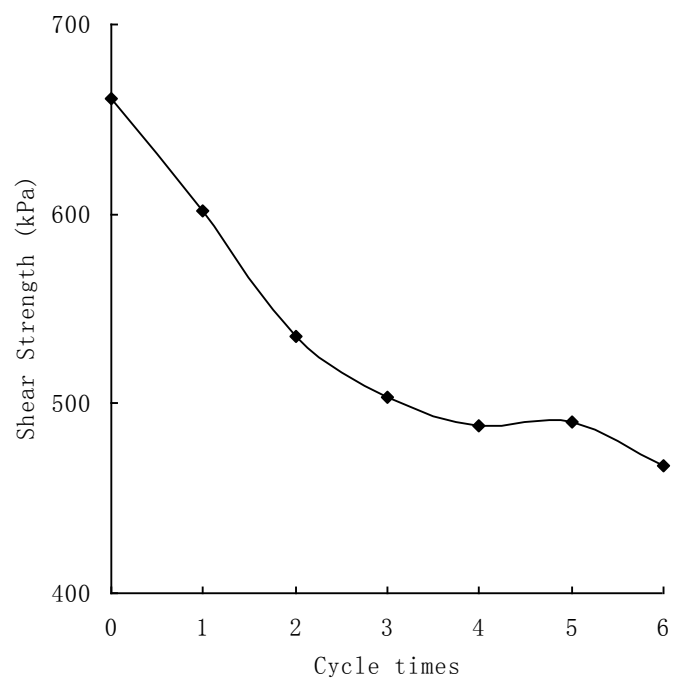

Fig. (6). Shear strength under freeze-thaw cycles.

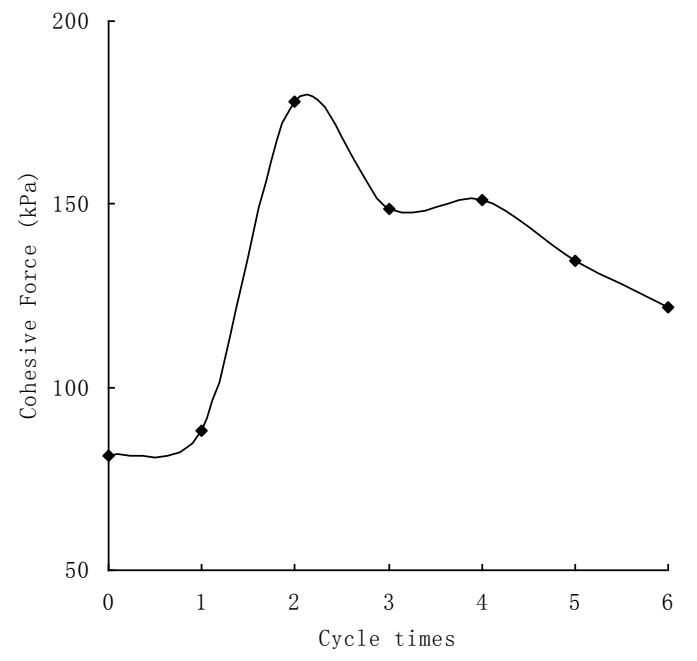

Fig. (7). Cohesion under freeze-thaw cycles. 


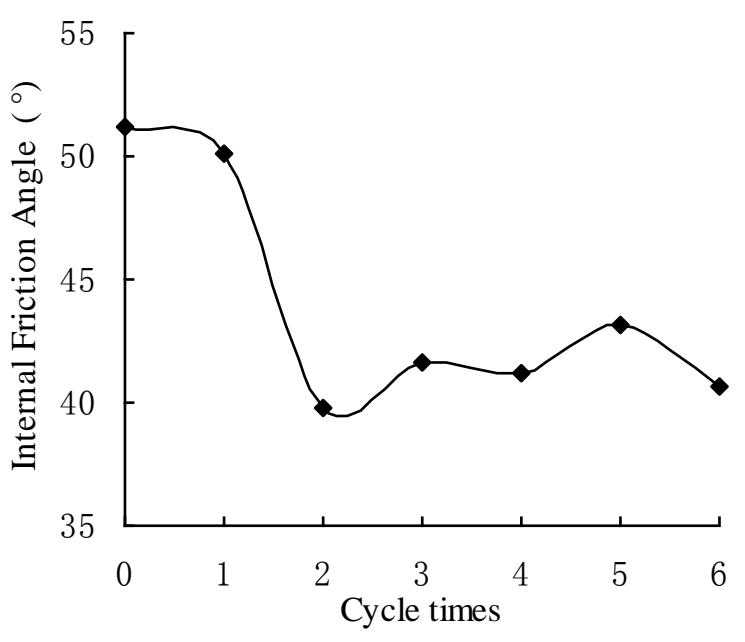

Fig. (8). Internal friction angle under freeze-thaw cycles.

normal stresses, it is difficult to get the actual value due to the relative error. As can be seen from Fig. (8), internal friction angle is decreased by $22 \%$ rapidly after 2 freezethaw cycles, and then its value is almost stable in the following freeze-thaw cycles, still 20\% after 6 freeze-thaw cycles. Therefore, freeze-thaw cycles have great influence on internal friction angle because crack in lime-fly ash loess makes strength decrease.

\subsection{Permeability Test}

Permeability tests were conducted on lime-fly ash loess after 90 days under 1-6 freeze-thaw cycles, and the result is shown in Fig. (9). As can be seen from Fig. (9), permeability coefficient of lime-fly ash loess increases with freeze-thaw cycles in general. Permeability coefficient after 1 cycle is $3.5 \times 10^{-6} \mathrm{~cm} \cdot \mathrm{s}^{-1}$, and it is increased by $50 \%$ after six freezethaw cycles. The reason is that volume expansion by frozen water can produce some tiny cracks. These tiny cracks will multiply with the increase of freeze-thaw cycles, resulting in improvement of penetration performance.

\section{CONCLUSION}

1). Uniaxial compressive strength of lime-fly ash loess increases with curing ages, 90d strength can reach 3.5 $\mathrm{MPa}$. And the strength of water-saturated lime-fly ash loess decreases obviously especially before 28 days, while later strength is only reduced by $2 \%$. Therefore, lime-fly ash loess has good water stability.

2). All uniaxial compressive strength of lime-fly ash loess decreases with different curing age and freeze-thaw cycles, $25 \%$ decreased for earlier strength and $15 \%$ decreased on average. In case of water-saturated lime-fly ash loess, freeze-thaw cycles have greater impact on uniaxial compressive strength. Average earlier strength has already reduced by $47.9 \%$, and the later strength still reduced by $14.6 \%$. Compared to the other cement-lime soil or clays, lime-fly ash loess has better freeze-thaw stability especially after 90 days. 90d strength is stable under different freeze-thaw cycles.

3). Shear stress and friction angle of lime-fly ash loess after 90 days decrease with freeze-thaw cycles, while

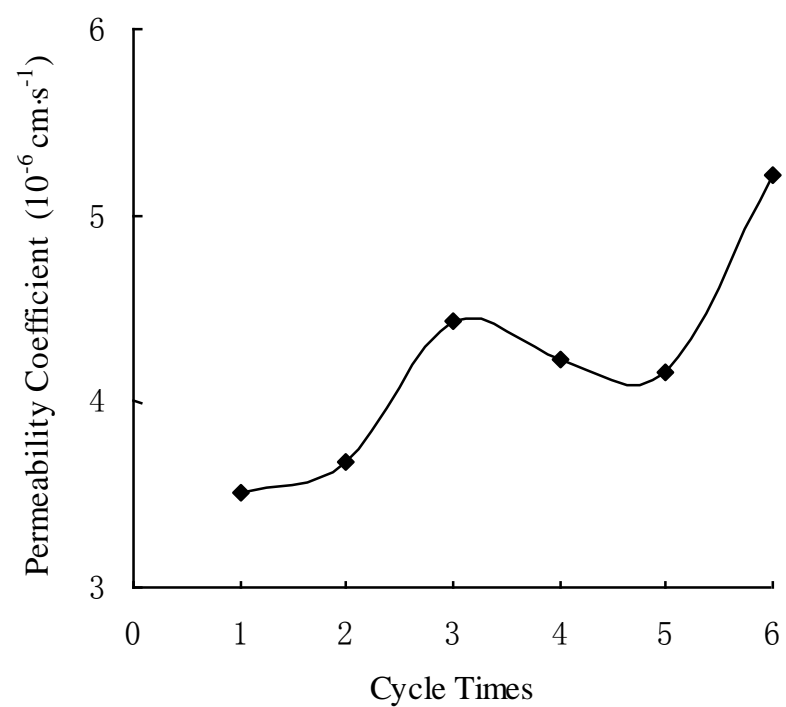

Fig. (9). Permeability coefficient under freeze-thaw cycles.

permeability coefficient increases with freeze-thaw cycles, so freeze-thaw cycles have a great impact on microstructures of lime-fly ash loess.

\section{CONFLICT OF INTEREST}

The authors have no conflict of interest to declare in relation to the content of this article.

\section{ACKNOWLEDGMENTS}

The writers would like to gratefully acknowledge the financial support provided by the Beijing Innovation Platform of Scientific research base construction, China.

\section{REFERENCES}

[1] X.B. Tu, A.K.L. Kwong, F.C. Dai, L. Tham, and G.H. Min, "Field monitoring of rainfall infiltration in a loess slope and analysis of failure mechanism of rainfall-induced landslides," J. Eng. Geo., vol. 105, pp. 134-150, Feb. 2009.

[2] Y.F. Zhang, and Z.Q. Zhang, "Influence factor analysis on strength of lime-fly ash loess," Engineering, vol. 5, no. 6, pp. 561-565, June 2013.

[3] T.T. Zhang, B.P. Zhang, Z.G. Tian, and D.H. Lv, "Study on engineering characteristic of lime-fly ash loess," Chinese J. Geotech. Eng., vol. 26, no. 5, pp. 719-721, May 2004. (in Chinese)

[4] E. Ovando-Shelley, and B.E. Perez, "Undrained behavior of clayey sands in load controlled triaxial tests," Geotechnique, vol. 47, no. 1 , pp. 97-111, Jan. 1997.

[5] Y.H. Yang, B. Liang, and L. Ding, "Experimental study on the strength behaviors of fly ash-lime or fly ash-cement". Chinese J. Geotech. Eng., vol. 23, no. 2, pp. 227-230, Feb. 2001. (in Chinese)

[6] Y. Feng, J. X. He, L. Liu, L. X. Yang, "Experimental study of the shear strength characteristics of fine-grained soil under freezing and thawing cycles," J. Glaciol. Geocryol. vol. 30, no. 6, pp. 10131017, June 2008. (in Chinese)

[7] Z.Q. Zhang, J. Shi, and P.Y. Zhang, "Research on strength characteristics of lime-fly loess". Sichuan Build. Sci. vol. 32, no.5, pp. 126-128, May 2006. (in Chinese)

[8] "Test method of soils for highway engineering," JTG E40-2007. the Ministry of Communications, China. 
[9] P. Viklander, "Permeability and volume changes in till due to cyclic freeze-thaw". Can. Geotech. J., vol. 35, no. 3, pp. 471-477, Mar. 1998.
[10] J.L. Qi, J.M. Zhang, and Y.L. Zhu, "Influence of freezing-thawing on soil structure and its soil mechanics significance". Chinese $J$. Rock Mech. Eng., vol. 22, pp. 2690-2694, Dec. 2003. (in Chinese)

Received: January 24, 2014

Revised: February 17, 2014

Accepted: March 12, 2014

(c) Zhang and Zhang; Licensee Bentham Open.

This is an open access article licensed under the terms of the Creative Commons Attribution Non-Commercial License (http://creativecommons.org/licenses/ by-nc/3.0/) which permits unrestricted, non-commercial use, distribution and reproduction in any medium, provided the work is properly cited. 